\title{
Optimizing for Viability - Revamping Vacuum Distillation Unit in a Brownfield Project
}

\author{
Saiful Anuar Mohd Mokhtar ${ }^{*}$, Marina Mosir ${ }^{2}$ \\ ${ }^{1}$ Principal Engineer (Process Design), Group Technology Solutions, PETRONAS, Kuala Lumpur, Malaysia \\ ${ }^{2}$ Staff Engineer (Fractionation), Group Technology Solutions, PETRONAS, Kuala Lumpur, Malaysia \\ *Corresponding author: saifulmokhtar@petronas.com
}

\begin{abstract}
Revamping an existing column in an operating plant for a higher throughput is always a challenge especially when the column is already operating at its rated capacity. This is particularly true for a Vacuum Distillation Unit (VDU) column which involves multiple product and pump-around streams and associated auxiliary units like a steam ejector system. Optimizing the design and operation of the column, hence, is inevitable to ensure the viability of a brownfield project as it avoids major modifications required to the column and its associated auxiliary systems. This paper discusses how optimization was done on the design and operation of an existing VDU column in an oil refinery, avoiding major modifications of the associated ejector, steam, cooling water, sour water systems and heat exchanger network, allowing a brownfield project to stay commercially viable.
\end{abstract}

Keywords: Brownfield, Optimization, Revamp, VDU.

\section{Introduction}

A case study of an existing VDU column at an existing refinery in Malaysia is deliberated in this paper. The VDU column was designed to operate at $9 \mathrm{mmHg}$ operating pressure with a throughput capacity of 3.5 kilo barrel per day (kbpd) of Low Sulfur Waxy Residue (LSWR) from an upstream Crude Distillation Unit (CDU). As part of business growth strategy of the refinery, the VDU column was contemplated to be debottlenecked to allow additional throughput of LSWR which is lighter than the existing throughput at $23 \mathrm{kbpd}$ to the unit. The lighter and higher LSWR throughput led to a higher noncondensable and condensable vapor flows at the top of the column, increasing the column internal loading massively, producing higher column operating pressure and causing additional burden to the overhead steam ejector system. Major modifications to the column shell diameters, steam ejectors and condensers were expected and the replacement of the equipment will require massive structural modification within an existing congested operating plant. On top of that, with the larger steam ejectors and condensers, major modifications to the associated steam generation system, cooling water system and sour water treating unit were expected. It was estimated that the total cost of modifications required was in the order of USD25 million and this may render the project uneconomical. Replacing the VDU column itself is not an option in view of the sheer complexity of the construction works required in the existing operating plant which require extended downtime of the refinery. The economic lost associated with the prolonged downtime outweigh the benefit of debottlenecking the column itself.

\section{Methodology}

One way to allow the project to still be economically viable is by optimizing the column operating conditions, column internal design efficiencies and exhausting all available heat duties within the pump- around and heat integration network to reduce the impact to the existing ejector system and minimizing the modifications to VDU unit. This was performed using industrially acceptable process simulators and an in-house sizing software for column internals.

Optimizing the column operating conditions includes increasing column bed efficiencies, adjusting the operating pressure, redistributing heat duties in the heat exchanger network, optimizing pump-around flow, adjusting column temperature profile and the column inlet temperature. This, in return, translates into changes of both mass and heat transfer profile within the column which resulted in the reduction of column internal liquid and vapour traffic and reduces the total load at the top of the column to the overhead steam ejector system.

\section{A. Debottlenecking a VDU Column}

Understanding how a VDU column works and the influence of the auxiliary systems to the VDU column operation is key in optimizing both the design and operation of the column itself. The VDU column under study was a typical 5 packed bed, 1 flashing section and 1 stripping section column design, operated under vacuum conditions at $9 \mathrm{mmHg}$ and was designed to fractionate heavy LSWR into product streams such as Light Vacuum Gas Oil (LVGO), Medium Vacuum Gas Oil (MVGO), Heavy Vacuum Gas Oil (HVGO) and Vacuum Residue (VR). See Figure 1 for the schematic of the VDU under study.

A 2-phase feed enters the VDU column flashing section via an upstream fired heater. Lighter vapor components will rise up the column to the wash, Bottom Pump-around (BPA), Middle Pump-around (MPA), Fractionation and Top Pump-around (TPA) sections to be further distillate to product streams 
through both the heat recovery pump-around beds and product purification beds. The heavier liquid components will go down the column bottom through the stripping section to ensure lighter portion can still be recovered before coming out of the VDU column as the Vacuum Residue (VR) product stream.

The VDU debottlenecking project will introduce lighter LSWR at an increased capacity from $3.5 \mathrm{kbpd}$ to $23 \mathrm{kpbd}$ into the VDU column. Due to the higher throughput, in order to allow for adequate separation within the column, a new fired heater was added upstream of the VDU column to provide additional $20 \mathrm{MW}$ heat duty to the VDU column. Hence, to meet the debottlenecking objectives, not only the column receives additional mass throughput but it also receives additional heat load to the column heat balance.

Through detailed tray-to-tray simulation and hydraulic sizing calculation performed at each of the column internals, it was observed that introducing additional mass throughput and heat load to the column causes the following:

1. Substantially huge vapor traffic rises up the column from the flashing section to the TPA section.

2. Higher pump-around duty requirement for all pumparound sections due to higher vapor traffic inside the column. This is to balance out the additional heat introduced by the new fired heater.

3. Due to higher vapor traffic in the column, lighter component slipped down to the VR section and compromises the VR product initial boiling point (IBP) specification.

4. Additional column pump down requirement at Fractionation and Wash Oil sections due to increase in liquid load.

5. Higher pressure drop across the column due to higher hold ups caused by higher liquid and vapor traffic.

The above changes to the column operating conditions will translate into major modifications to the VDU column and its auxiliary systems if no optimization was performed on the column internal design and operation.

\section{B. VDU Column Modification without Optimization}

The conventional way of debottlenecking a VDU column will involve total revamp of the column itself which could include total replacement of the column internals to higher performance internals, increasing the column inlet and outlet nozzles, allowing larger column diameter and to the extreme of total replacement of the VDU column itself. To manage the additional heat load introduced into the VDU column heat balance, additional external cooling or heat sinks need to be introduced either through introduction of additional heat exchangers in the heat exchanger network or provision of new water or air coolers.

In addition to the above, higher vapor load which exits the top of the column, consisting of both condensable and noncondensable hydrocarbon components could result in a massive multi-stage ejector modification requirement. To support the ejector modification, major modifications to the associated steam generation system, cooling water system and sour water treating unit were expected. Section 3 summarizes the modification required should optimization was not opted.

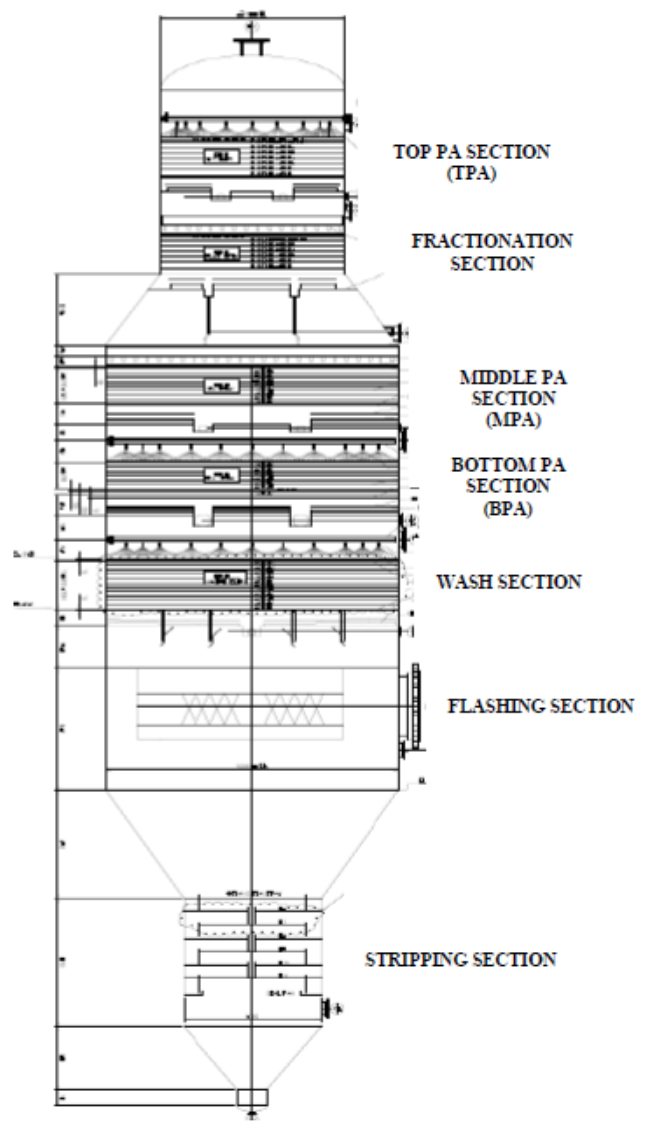

Fig. 1. Vacuum distillation column

\section{VDU Column Modification with Optimization}

To prevent major modifications to the VDU column, the column design and operation was optimized before modification scope were identified. The VDU column operating parameters and each section within the VDU column was examined in details and iterative simulations were performed to ensure each bed within the VDU column can be fully optimized. Below optimization approach was applied to minimize the scope of the VDU column modifications:

1. Fired Heater Coil Outlet Temperature (COT) into the VDU column was reduced from the design operating temperature to the lowest operating temperature at which the column is still able to allow good separation to occur within the column. This optimizes the heat balance within the VDU column and the capital investment required to the handle the additional heat within the heat exchanger network.

2. Column top vacuum operating pressure was increased from the design operating pressure to the maximum operating pressure at which the column is still able to accommodate to good separation to occur within the column. This reduces the amount of condensable and noncondensable at the vapor outlet of the VDU column to the 
ejector system, avoiding major modifications to the ejector system and associated steam, cooling water and sour water treating units.

3. For all heat recovery pump-around beds within the VDU column i.e. TPA, MPA and BPA, high efficiency packing type with additional surface area was selected. This type of packing selected does not sacrifice the void fraction i.e. the capability to withstand higher load.

4. The heat recovery through heat exchanger network was optimized to achieve maximum heat integration within the VDU unit and minimize capital investment for modification of existing heat exchangers except for additional water or air coolers for final heat rejection. This is achievable through the use of higher efficiency bed at both TPA and MPA sections allowing better heat recovery at lower pump-around flow which reduces both the column internal vapor and liquid traffic and improves heat recovery in the highly integrated heat exchanger network.

5. For all fractionation packing bed within the VDU unit i.e. fractionation section and wash section, latest development in technology of hybrid packed bed was chosen to provide better performance i.e. higher void fraction without sacrificing the efficiency i.e. surface area. By using the high efficiency packed bed, hydraulic limitation was reduced without having to increase column diameter while separation and product quality are met. This avoid any modification to the VDU column shell itself.

With the optimization approaches above, it was observed that the VDU column total internal vapor and liquid traffic was greatly reduced throughout the column while maintaining the products separation and quality. The optimization has also resulted in smaller vapor condensable and non-condensable flows at the top of the column. These avoids major modifications to the VDU column, its auxiliary systems and the heat exchanger network, significantly reducing capital investment of the brownfield project. Section 3 summarizes the modification required with optimization being executed.

\section{Results and Discussion}

The modifications required for the VDU column with and without the optimization are listed below in Table 1.

The optimization of the VDU column operating conditions and internal design avoids replacement of the 1st Stage Ejector (largest ejector system) and associated steel structure for the ejector system and requirement for a new Cooling Water Package and associated interconnected piping, a new Steam Generation Package and associated interconnected piping, a new Sour Water Treating Unit and additional heat exchangers, cooling water or air coolers in the heat exchanger network. It is estimated that the total cost avoidance is in the order of USD25 million as a result of the optimization work. This allows the project to stay economically viable.

The project has recently undergone a performance test run (PTR) and proven to be able to meet the desired performance guarantee.

Table 1

VDU Revamp Scope with and without optimization

\begin{tabular}{|c|c|c|}
\hline & $\begin{array}{c}\text { Without Optimization } \\
\end{array}$ & With Optimization \\
\hline \multirow[t]{5}{*}{ Base Scope } & $\begin{array}{l}\text { VDU Column Shell and Nozzle Modification } \\
\text { - VDU Column shell diameter increase }(+15 \% \text { diameter }) \\
\text { - VDU Column height increase }(+10 \% \text { high). } \\
\text { - Increase TPA return nozzle size and change spray } \\
\text { distributor }(+25 \% \text { increase in size). }\end{array}$ & $\begin{array}{l}\text { VDU Column Shell and Nozzle Modification } \\
\text { - Increase TPA return nozzle size and change spray distributor }(+25 \% \\
\text { increase in size). }\end{array}$ \\
\hline & $\begin{array}{l}\text { Packing Beds and Internal Replacement } \\
\text { - Replacement of the TPA, MPA and BPA section to high } \\
\text { capacity type of packed bed without reducing the } \\
\text { efficiency. } \\
\text { - Replacement of the TPA, MPA and BPA section to high } \\
\text { capacity type of packed bed without reducing the } \\
\text { efficiency. }\end{array}$ & $\begin{array}{l}\text { Packing Beds and Internal Replacement } \\
\text { - Replacement of the TPA, MPA and BPA section to high capacity type } \\
\text { of packed bed without reducing the efficiency. } \\
\text { - Replacement of the TPA, MPA and BPA section to high capacity type } \\
\text { of packed bed without reducing the efficiency. Latest development in } \\
\text { technology of hybrid packed bed was chosen. }\end{array}$ \\
\hline & $\begin{array}{l}\text { Replacement of Top Pump around (TPA) Air coolers (+25\% } \\
\text { duty) }\end{array}$ & Replacement of Top Pump around (TPA) Air coolers (+25\% duty) \\
\hline & Replacement of LVGO Pumps (+150\% capacity) & Replacement of LVGO Pumps (+40\% capacity) \\
\hline & $\begin{array}{l}\text { Replacement of Middle Pump around (MPA) / MVGO Pumps } \\
(+93 \% \text { capacity) }\end{array}$ & $\begin{array}{l}\text { Replacement of Middle Pump around (MPA) / MVGO Pumps (+95\% } \\
\text { capacity) }\end{array}$ \\
\hline \multirow[t]{4}{*}{$\begin{array}{l}\text { Additional } \\
\text { Scope }\end{array}$} & $\begin{array}{l}\text { Replacement of 1st Stage Ejector (largest ejector system) } \\
\text { (increase from } 15 \mathrm{~m} \text { length to } 42 \mathrm{~m} \text { length) and associated steel } \\
\text { structure for the new ejector system. }\end{array}$ & $\begin{array}{l}\text { Replacement of Third Stage Ejector (smallest ejector system) (increase } \\
\text { from } 1 \mathrm{~m} \text { length to } 1.6 \mathrm{~m} \text { length). }\end{array}$ \\
\hline & $\begin{array}{l}\text { New Cooling Water Package and associated interconnected } \\
\text { piping }(+1670 \mathrm{~m} 3 / \mathrm{hr} \text { ton/hr capacity) }\end{array}$ & Replacement of VR/LSWR Cooler (+7\% duty) \\
\hline & $\begin{array}{l}\text { New Steam Generation Package and associated interconnected } \\
\text { piping ( }+59.5 \text { ton/hour capacity) }\end{array}$ & \\
\hline & New Sour Water Treating Unit (+59.5 ton/hr capacity) & \\
\hline
\end{tabular}




\section{Conclusion}

In conclusion, optimization of a column operating conditions and design is critical, particularly for a complex column like a VDU column, especially when the column is already operating at its rated capacity in a brownfield project. A case study of a VDU column in an oil refinery in Malaysia indicates that massive modifications are required if optimization is not done on the column operating conditions which add unnecessary capital expenditures and may render the project economically unviable. However, optimization of the operating conditions should be done cautiously with adequate verification work being performed. This is to ensure that the column performance is not jeopardized and performance guarantee can still be met by the project.

\section{References}

[1] J. M. Douglas, "Complex Distillation Columns," in Conceptual Design of Chemical Processes, International Edition. Massachusetts, USA: MacGraw-Hill Book Company, 1988, Part IV Appendixes, sec. A-5, pp. 466-478.

[2] H. Z. Kister, "Column Process Design, Optimization and Shortcut Calculations" in Distillation Design, New York, USA: McGraw-Hill Book Company, 1992, Chapter 3, Sec. 3.1, pp. 87-105.

[3] H. Z. Kister, "Reflux and Intermediate Feed Distribution and Liquid Redistribution in Packed Towers" in Distillation Operation, New York, USA: McGraw-Hill Book Company, 1990, Chapter 3, Sec. 3.1-3.12, pp. 35-79.

[4] L. Hugo, "Atmospheric Crude Tower" in Hysys. Process Manual, Calgary, Canada: Hyprotech Limited, 1998, Chapter R1, pp. R1-1 - R114.

[5] Aspen Tech, "Advanced Column" in Advanced Process Modeling Using Hysys, Massachusetts, USA, Aspen Technology, Inc, 2004, Chapter 3, pp. 3-1-3-18. 